\title{
Correction to: Runs of homozygosity have utility in mammalian conservation and evolutionary studies
}

\author{
Anna Brüniche-Olsen ${ }^{1}\left(\mathbb{D} \cdot\right.$ Kenneth F. Kellner ${ }^{1}$ (i) $\cdot$ Chase J. Anderson ${ }^{2} \cdot$ J. Andrew DeWoody ${ }^{1,2}$ (])
}

Published online: 10 September 2018

(c) Springer Nature B.V. 2018

\section{Correction to: Conservation Genetics \\ https://doi.org/10.1007/s10592-018-1099-y}

The fourth author's name was incorrect in the original publication and correct author name is given in this Correction.

The original article can be found online at https://doi.org/10.1007/ s10592-018-1099-y.

$\triangle$ Anna Brüniche-Olsen abruenic@purdue.edu

1 Department of Forestry \& Natural Resources, Purdue University, West Lafayette, IN 47905, USA

2 Department of Biological Sciences, Purdue University, West Lafayette, IN 47905, USA 